\title{
Contabilidade de Custos na Gestão Hospitalar: Um Estudo de Caso de Outsourcing no Contexto do Hospital Universitário de Juiz de Fora
}

\author{
Valéria Romão Pasqualini Nerio \\ Residência em Gestão Hospitalar pelo Hospital Universitário da Universidade Federal \\ de Juiz de Fora - UFJF \\ Mestrado em andamento em Saúde Coletiva com enfoque na linha de Política, \\ Gestão e Avaliação de Sistemas e Programas de Saúde pela Universidade \\ Federal de Juiz de Fora - UFJF \\ Rua José Lourenço Kelmer, s/n. São Pedro. Juiz de Fora/MG. CEP: \\ 36.036-900 \\ E-mail: valeria.ufjf@live.com
}

\section{RESUMO}

Partindo-se de pressupostos de gestão com vistas ao adequado funcionamento das instituições públicas, nota-se a presença de ferramentas gerenciais como a gestão estratégica de custos. Nesta pesquisa, realizou-se o levantamento de custos entre duas opções de impressões em papel realizadas no escopo do Hospital Universitário de Juiz de Fora (HU-UFJF/EBSERH), quais sejam: (a) contrato de outsourcing de impressão; (b) impressão via máquina de reprografia de propriedade do $\mathrm{HU}$, disponíveis no ativo imobilizado da instituição. Buscou-se analisar a relação de 'vantajosidade' entre realizar manutenção em uma máquina de reprografia ou aditivar o contrato de outsourcing de impressão. O principal resultado da pesquisa evidencia que o custo de impressão via máquina da reprografia mostra-se 53\% mais econômico que o custo de imprimir via contrato de outsourcing. Nessa perspectiva, os custos fixos envolvidos na opção de contratação de outsourcing geram aparentes desperdícios econômicos e financeiros.

Palavras-chave: Administração pública. Gestão hospitalar. Contabilidade de Custos.

\section{Accounting of Costs in Hospital Management: A Case Study of Third Parties in the Context of the University Hospital of Juiz de Fora}

\section{ABSTRACT}

Based on management assumptions, with a view to the proper functioning of public institutions, we can note the presence of management tools such as strategic cost management. In this research the costing between two options of paper impressions realized within the scope of the University Hospital of Juiz de Fora (HU-UFJF / EBSERH) was carried out, which are: (a) contract of outsourcing of printing; (b) printing via the reprographic machine owned by the HU, available in the institution's fixed assets. We sought to analyze the advantageous relationship between performing maintenance 
on a reprographic machine or adding to the outsourcing contract for printing. The main result of the research shows that the cost of printing by the machine of reprography is $53 \%$ more economical than the cost of printing via an outsourcing contract. From this perspective, the fixed costs involved in the outsourcing contracting option generate apparent economic and financial waste.

Keywords: Public administration. Hospital management. Cost accounting.

\section{INTRODUÇÃO}

O Hospital Universitário da Universidade Federal de Juiz de Fora, HUUFJF/EBSERH, possui três unidades: Unidade Santa Catarina, Unidade Dom Bosco e Centro de Atenção Psicossocial (CAPS). Atua na prestação de serviços assistenciais em regime público, desenvolvendo atividades de ensino, pesquisa e extensão.

O presente artigo visa identificar e comparar os custos envolvidos nos processos de impressão utilizados no HU-UFJF, sejam eles incorridos pela utilização de impressoras dentro do escopo hospitalar de um contrato de outsourcing de impressão ou estejam os custos relacionados à utilização da máquina de reprografia de propriedade da instituição. Esta apuração torna-se necessária, tendo em vista que a manutenção corretiva e preventiva desses equipamentos tem sido cada vez mais frequente. Além disso, para cada dispositivo utilizado, há peculiaridades que devem ser analisadas com o intuito de se observar qual método demonstra ser vantajoso para o Hospital.

Segundo Leone (2010), o uso da Contabilidade de Custos para fins gerenciais resulta da tradução do controle de custos das operações, com o objetivo de verificar o comportamento constante de padrões previamente estabelecidos. Nesse sentido, depreende-se que as principais causas dispendiosas são em decorrência das disfunções operacionais.

Ademais, este estudo se baseia no formato de análise da contabilidade de Custos que é defendida por Leone em possuir a pretensão de "fornecer informações 
aos diversos níveis gerenciais que a solicitam para atender a suas funções de planejamento e de tomada de decisões" (Leone, 2010).

Paralelamente, utiliza-se como suporte de planejamento o Plano de Ação $(5 \mathrm{~W} 2 \mathrm{H})$, pois permite, de modo simples, que informações básicas e primordiais sejam evidenciadas e, por conseguinte, surjam propostas minuciosas para tratativa do problema organizacional (Silva, Roratto, Servat, Dorneles, \& Polacinski, 2013).

Nesse ínterim, propõe-se responder à seguinte questão: Tendo em vista o contexto econômico-financeiro do Hospital Universitário, deve-se dar manutenção na máquina de reprografia ou ampliar a utilização do contrato de Outsourcing? Para responder à pergunta de pesquisa, estabelece-se um objetivo geral, que consiste em identificar os custos de produção de impressos do HU-UFJF/EBSERH, objetivando a análise de 'vantajosidade' econômico-financeira nas tomadas de decisões de curto prazo.

A Gestão Estratégica de custos possui uma abordagem para melhoria contínua de desempenho, ao utilizar informações mais relevantes para as tomadas de decisões, como as análises de custos (Alves, 2012).

Para responder à questão-problema, foram desenvolvidos dois objetivos específicos, quais sejam: levantar o quantitativo de produção de impressos pelas máquinas de reprografia e impressão no quadrimestre de setembro a dezembro de 2016; e analisar comparativamente os custos envolvidos nos processos de impressos do quadrimestre de setembro a dezembro de 2016.

Portanto, por meio deste estudo, pretende-se oferecer subsídios para uma gestão eficiente de custos, tendo em vista que os recursos organizacionais demonstram ser escassos, e a organização não dispõe de sistema de apuração de custos.

\section{MÉTODO}

No tocante à técnica de coleta de dados, utilizou-se a pesquisa documental escrita primária, de fonte pública e bibliográfica. Para Lakatos e Marconi (2003), esta é 
caracterizada por abranger toda bibliografia pública desenvolvida em relação ao tema abordado, ou seja, não resulta de uma mera repetição, mas possibilita uma nova abordagem do tema.

Este estudo se baseia na utilização da Contabilidade de Custo como instrumento de mensuração de informações, visando identificar as principais limitações e potencialidades de contrato de outsourcing que impacta financeiramente a organização hospitalar em $R \$ 3.021 .984,23$ (três milhões, vinte e um mil e novecentos e oitenta e quatro reais e vinte três centavos) por ano, em âmbito nacional.

Essa mensuração será utilizada como instrumento de análise das ações administrativas, objetivando identificar gastos que podem sofrer modificações. Se o método for bem-sucedido, será possível demonstrar a natureza do problema em termos de preço, volume ou prática organizacional.

Diante disso, este estudo busca identificar os custos de produção de impressos do HU-UFJF/EBSERH, objetivando a análise de 'vantajosidade' econômico-financeira nas tomadas de decisões de curto prazo.

Cabe destacar que, no contexto do HU-UFJF, não havia nenhum sistema de custeio implementado. Esse sistema pode ser compreendido como: "os métodos de custeio definem como deve ocorrer a mensuração para apuração dos custos dos produtos". (Padoveze, 2011).

Inicialmente, buscou-se a investigação junto aos profissionais envolvidos no controle e monitoramento das operações de impressões e reprografia.

Foram analisados, no total, três modelos de impressoras, quais sejam: Lexmark MX611; Lexmark MS812; e Lexmark MS812, que resultaram no quantitativo de 47 máquinas, apurado no período do último quadrimestre do ano de 2016 (setembro a dezembro/2016). Além disso, realiza-se a análise de uma máquina de reprografia de configuração Gestetner CP6143L.

Destaca-se que o setor de Reprografia contém duas máquinas, porém ambas se encontram inoperantes. Além disso, a última operação da supracitada ocorreu em 26 de dezembro de 2016. 
Contabilidade de Custos na Gestão Hospitalar: Um Estudo de Caso de Outsourcing no Contexto do Hospital Universitário de Juiz de Fora Valéria Romão Pasqualini Nerio

No segundo momento, foram selecionados os setores de Almoxarifado, Reprografia e Informática para o fornecimento das informações técnicas, relatórios estatísticos dos dispositivos, bem como o controle de gastos, a fim de se mensurar os custos envolvidos nos processos produtivos envolvidos.

Além disso, foram identificados fatores relevantes como os dados quantitativos obtidos em planilhas de controle do Almoxarifado e Informática, uma vez que não há sistema de custeio implementado para a gestão de custos hospitalares na organização.

Não obstante, utilizando-se pesquisa documental, verificou-se, em sistema de informação interno da organização, denominado Sistema de Gestão (SIG), a apuração do contrato de Outsourcing $n^{\circ}$ 22/2015, com vigência compreendida entre o período de agosto de 2015 a agosto de 2018, de impressão corporativa, cuja relação obrigacional é estipulada pelo direito de uso de equipamentos (Hospitalares, 2017).

Portanto, tal contrato se prolonga a partir da EBSERH-Sede, que possui a autonomia de incluir a prestação de serviços às suas filiais, bem como a manutenção e inclusão de consumíveis necessários.

Salienta-se que todos os dados foram coletados junto aos setores envolvidos durante a execução deste trabalho: Divisão de Apoio Diagnóstico e Terapêutico (DADT), Divisão Administrativa Financeira (DAF), Setor de Administração (SA), Setor de Avaliação e Controladoria (SAC), Setor de Gestão de Processos e Tecnologia da Informação (SGPTI), Unidade de Compras (UCOMP), Unidade de Apoio Operacional (UAO) e o serviço de Reprografia.

Para a construção de referencial teórico, utilizou-se pesquisa bibliográfica, tendo em vista que sua vantagem está na possibilidade de maior cobertura com conteúdo já produzido e registrado (Gil, 2002).

Esta estratégia mostrou-se apropriada à temática, uma vez que as ações organizacionais analisadas demonstram dispor de amplitude descritiva e exploratória. Para a análise de dados, utilizou-se estatística descritiva, construídos em software tabulados e tratados por meio do software Microsoft Excel, versão 2013. 
Contabilidade de Custos na Gestão Hospitalar: Um Estudo de Caso de Outsourcing no Contexto do Hospital Universitário de Juiz de Fora Valéria Romão Pasqualini Nerio

Segundo Diehl, Souza e Domingos (2007), a estatística descritiva compreende o manejo dos dados para resumi-los ou descrevê-los, sem ir além, isto é, sem procurar inferir qualquer coisa que ultrapasse os próprios dados. A escolha desse método justifica-se em função do procedimento técnico de coleta de dados, ocorrido pela obtenção das amostras em campo, pelo estudo de caso.

Por fim, para compreensão do problema abordado neste estudo, realizou-se uma Pesquisa de Campo, cuja definição norteia-se pelo levantamento de dados do próprio local onde os eventos ocorrem (Lakatos \& Marconi, 2003).

\section{TOMADAS DE DECISÕES BASEADAS EM CONTABILIDADE DE CUSTOS}

Na perspectiva de gestão, os custos possuem definição diversa da notação contábil, os quais estão preocupados em tratar o desempenho retrospectivo das organizações, ao passo que a gestão se concentra, essencialmente, nas perspectivas futuras (Colodetti, 2015).

Nesse sentido, o constante monitoramento de eficiência, eficácia e efetividade de alocação de recursos pode significar oportunidades de custeio perdidos, quando não otimizados.

Segundo Crepaldi (2017), a Contabilidade de Custo surge como uma ferramenta de mensuração monetária dos estoques e de todos os custos da fabricação de um produto e do resultado muito útil.

Nesse sentido, a Contabilidade de Custo se caracteriza como um meio de analisar os custos fixos no processo de produção por métodos de custeamento por absorção ou global, por meios específicos para cada atividade, possibilitando, ao final da produção, ter o produto final com o custo relativo de sua produção. Contudo, existem custeios que alocam somente custos variáveis relativos à produção, mas é necessário avaliar qual o melhor para se realizar com confiabilidade os registros, podendo-se obter maior proveito de cada método e não prejudicando a Empresa (Crepaldi, 2017). 
Contabilidade de Custos na Gestão Hospitalar: Um Estudo de Caso de Outsourcing no Contexto do Hospital Universitário de Juiz de Fora Valéria Romão Pasqualini Nerio

Nota-se que a Contabilidade de Custo, atualmente, torna-se uma ciência de grande importância no campo empresarial que fornece as ferramentas necessárias para se alcançar resultados de impacto organizacional.

$\mathrm{Na}$ perspectiva da gestão hospitalar, principalmente em hospital de ensino, tem-se que a Contabilidade de Custo é uma forma de prover a informação necessária para a gerência eficiente de recursos de todos níveis, desenvolvendo padrões que permitem aos gestores prever gastos em recursos humanos e não pessoais, em curtos períodos de tempo (Dallora \& Forster, 2008).

As ações de impressões são atividades cotidianas que merecem atenção, haja vista que os custos envolvidos impactam a gestão financeira da organização.

Nesse sentido, os hospitais devem ser geridos para prestação de serviços hospitalares resolutivos, qualitativos com o menor custo possível. Com este enfoque do menor custo, sem perder em qualidade e resolutividade, é que os hospitais buscam, atualmente, uma gestão financeira equilibrada e saudável (Vieira, 2015).

No próximo tópico, serão explorados os principais conceitos de Contabilidade de Custo.

\section{CONTRATO DE OUTSOURCING}

O contrato de outsourcing caracteriza-se pela relação comercial com empresas externas à organização, cuja ação se dá pela gestão de uma parte da infraestrutura dessa organização (Menezes, 2014).

Não obstante, para atendimento de parte das demandas de impressões do Hospital Universitário de Juiz de Fora, foi verificada a existência contratual vigente de outsourcing.

Menezes (2014) afirma que esta relação se configura em parceria com reflexo de terceirização. Além disso, põe em questão enclaves relacionados aos fatores de gestão de custos e autonomia de gestão. 
Na medida em que as empresas buscam uma melhor gestão dos seus custos, maior eficiência dos seus processos e uma otimização de estrutura, a contratação traz benefícios que desoneram a atenção da organização (Anjos, 2016).

Porém, por outro lado, o autor abre espaço para que um terceiro passe a integrar sua estrutura e administre alguns de seus processos, o que gera naturalmente uma dependência mútua de ambas as empresas nessa relação comercial.

Nesse contexto, Napoleão Filho, Alves, Pereira, Barreto, Nunes e Pacheco (2013) mencionam a motivação financeira para a adoção de outsourcing nas aquisições das organizações públicas: "muitas instituições públicas estão terceirizando suas necessidades de impressão para reduzir os custos de manutenção e proteger-se do investimento em impressoras que se tornam obsoletas".

Nesse viés, este estudo busca demonstrar até que ponto esta desoneração é vantajosa quando confrontada com a autogestão de equipamentos de impressos, nesse caso, advindos da produção por máquina de reprografia.

Ressalta-se que os contratos de outsourcing possuem vantagens e desvantagens, sendo demonstradas na Figura 1.

\begin{tabular}{|l|l|}
\hline \multicolumn{1}{|c|}{ Vantagens } & \multicolumn{1}{c|}{ Desvantagem } \\
\hline Atualização Tecnológica sem Investimentos & Elevados Custos de um Eventual Regresso. \\
\hline Gerenciamento de Equipamentos em Rede & Dependência da Empresa Contratada. \\
\hline Serviço Especializado & $\begin{array}{l}\text { Qualidade no Serviço Prestado pode sofrer } \\
\text { variações. }\end{array}$ \\
\hline Logística Consumível & \begin{tabular}{l} 
Eventual surgimento de Custos Ocultos. \\
\hline $\begin{array}{l}\text { Aprimoramento Tecnológico que possibilita o o } \\
\text { aumento de produtividade }\end{array}$
\end{tabular}$\quad \begin{array}{l}\text { Desmotivação de Pessoal por Instabilidade do } \\
\text { Processo. }\end{array}$ \\
\hline
\end{tabular}

Figura 1. Principais Vantagens e Desvantagens em Contratos de Outsourcing

Fonte: Adaptado de NAPOLEÃO FILHO et al. Eficiência na Administração Pública: o modelo de outsourcing de impressão na Universidade Federal de Santa Catarina. Universidade Federal de Santa Catarina. XIII Colóquio de Gestión Universitaria en Américas. Buenos Aires, Argentina, 27 a 29 de novembro de 2013. 
Corroborando as principais vantagens e desvantagens de contrato de outsourcing, nota-se, no contexto do Hospital Universitário de Juiz de Fora, por exemplo, em função da utilização excessiva de determinada impressora: a frequente manutenção pela utilização inadequada; e o comprometimento do clima organizacional, por vezes gerando desmotivação entre os colaboradores.

Nesse sentido, ocorre o deslocamento de demanda de impressões advindas da reprografia quando estas máquinas também estão em manutenção, ou seja, os profissionais envolvidos no setor de reprografia podem estar sujeitos a situações de conflitos no cotidiano.

\section{ESTUDO DE CASO: COMPOSIÇÃO DE CUSTOS}

Optou-se por selecionar o escopo temporal compreendido entre os meses de setembro a dezembro de 2016, tendo em vista que o controle de custos de impressão na organização deu-se a partir desse período. Além disso, a máquina de reprografia encontrava-se em manutenção desde 26 de dezembro de 2016, possibilitando assim as proporcionalidades de rateio dos dados de produção de impressos realizados pelos equipamentos.

Não obstante, este artigo também apresenta informações referentes às impressoras no primeiro quadrimestre do ano de 2017, a fim de se acompanhar a evolução dos custos envolvidos na impressão por outsourcing. Salienta-se, ainda, que alguns equipamentos foram desligados durante a investigação desses quadrimestres. Essas informações serão pontuadas no próximo tópico, para melhor análise.

\subsection{Reprografia}

O setor de reprografia do HU-UFJF/EBSERH é caracterizado por possuir duas máquinas, sendo que ambas pertencem ao ativo imobilizado da organização.

Rodrigues (2014) define o ativo imobilizado como sendo "formado por todo ativo tangível ou corpóreo de natureza relativamente permanente, no qual são destinadas as 
operações de negócios de uma empresa". Logo, entende-se que tais bens possuem previsão de vida útil, depreciação e deterioração no decurso do tempo.

Desse modo, as máquinas de reprografia pertencem à instituição, ou seja, conferem maior autonomia gerencial. Há de se considerar a inclusão de custos adicionais, como manutenção e insumos consumíveis de cartuchos.

A seguir, especifica-se uma das máquinas, além de insumos necessários ao funcionamento, já se descrevendo os custos envolvidos na produção de impressos.

Foram analisados cartuchos Gestetner CP6143L CopyPrinter, cujos valores médios foram considerados das aquisições dos últimos três processos de compras. Utilizaram-se, como fonte de dados, planilhas de acompanhamento do setor de Almoxarifado.

Nessa variável de insumo (cartuchos), estão inclusos os dados sobre a quantidade de gastos dos últimos pedidos de cartuchos que foram solicitados nos meses de julho de 2016 e outubro de 2016, tendo a quantidade solicitada sido de 15 e 10 cartuchos respectivamente.

Na confecção da planilha de análise de custos, o cálculo foi baseado no valor médio entre os mesmos. O pedido consecutivo dar-se-ia, provavelmente, no mês de janeiro de 2017, contudo a máquina encontra-se inoperante. O Hospital Universitário de Juiz de Fora possuía, em seu ativo imobilizado, duas máquinas de dados de Reprografia.

Contudo, para fins de análise, consideraram-se apenas os dados de uma máquina, pois não foi possível apurar, com maior precisão, os dados da segunda, sendo que esta encontrava-se em manutenção.

Em pesquisa de campo, constatou-se que as performances das máquinas são similares a partir da configuração técnica. Logo, para fins de análise, a investigação de uma máquina demonstrou ser suficiente no desenvolvimento deste estudo.

Para que o funcionamento da máquina ocorra de modo adequado, é necessária a utilização do Master. Este insumo é utilizado para fornecer maior estabilidade de impressão ao reduzir falhas e riscos, sendo utilizados, em média, 2 por mês para que 
se atenda todas as demandas do Hospital. O valor médio apurado se deu no mesmo lapso temporal dos demais insumos.

Em se tratando de custeio para produção de impressos por reprografia, há de se considerar, ainda, o gasto médio de papel para produção que atenda as demandas do hospital. Nesse caso, o consumo médio apurado foi da ordem de 150 resmas (contendo 500 folhas por resma). Logo, verificou-se a média de 75.000 impressões por mês, sendo que, para cada pacote de 500 folhas, o custo é de $R \$ 14,47$ (quatorze reais e quarenta e sete centavos).

Por fim, o gasto médio de manutenção corretiva/preventiva ocorre geralmente no intervalo de 4 a 5 meses. Tal informação foi adquirida junto ao Setor Reprografia, sendo que o custo médio da prestação desse serviço é de $\mathrm{R} \$ 300,00$ (Trezentos Reais) por dispensa de licitação.

Após a realização de levantamento de reprografia, realizou-se o mesmo com as impressoras utilizadas por meio do contrato de outsourcing, já que o objetivo era analisar comparativamente os custos de ambos.

\subsection{Impressoras}

Com vistas à investigação deste estudo, as informações foram obtidas por meio de Pesquisa Documental e Pesquisa de Campo. O contrato de outsourcing que se encontrava vigente na instituição perpassou variações quantitativas de dispositivos ativos, tendo em vista que houve necessidade de redução de custos, em função das metas da organização em manter o custo de impressão por folha em $R \$ 0,08$ (oito centavos). Demonstra-se, na Tabela 1, o quantitativo de impressoras que estavam ativas até o mês de junho de 2017. 
Contabilidade de Custos na Gestão Hospitalar: Um Estudo de Caso de Outsourcing no Contexto do Hospital Universitário de Juiz de Fora

Valéria Romão Pasqualini Nerio

Tabela 1

Equipamentos Cedidos por Outsourcing no HU-UFJF/EBSERH

\begin{tabular}{lcc}
\hline \multicolumn{1}{c}{ Equipamentos } & Quantitativo Total em 2016 & Quantitativo Total em 2017 \\
\hline Lexmark MX 611 & 20 & 20 \\
Lexmark MS 812 & 18 & 18 \\
Lexmark X 792 & 9 & 6 \\
Lexmark X 950 & 1 & 0 \\
\hline Totais & $\mathbf{4 7}$ & $\mathbf{4 3}$ \\
\hline
\end{tabular}

Nota. Fonte: Elaborada pela autora.

Para melhor detalhamento deste estudo, se faz mister mencionar que a impressora Lexmark $X 950$ foi retirada em setembro de 2016, pois o aluguel estava muito oneroso em comparação às demais e, portanto, não integra a apuração de custos. Seu custo era de $R \$ 1.150,00$. Sobre a apuração de equipamentos, esta ocorreu no último quadrimestre de 2016 e, no ano de 2017, a apuração está compreendida no período de janeiro a junho.

A apuração de custos foi detalhada conforme as disposições produtivas do Hospital Universitário das Unidades de Santa Catarina e Dom Bosco, ou seja, compreendeu todo o Hospital Universitário, cujas impressões produzidas são coloridas e/ou preto e branco.

No que tange ao contrato de outsourcing, ocorria o fornecimento de serviços e equipamentos em impressão, adquiridos por licitação. A prestação de serviços de impressão orientava-se conforme a cláusula primeira do contrato vigente (objeto), conforme assevera o Termo De Referência e seus encartes, edital do Pregão Eletrônico n 06/2015: "O objeto do presente contrato é a prestação de serviços de impressão corporativa, compreendendo a cessão de direito de uso de equipamentos novos e de primeiro uso, incluindo a prestação de serviços de manutenção preventiva e corretiva, fornecimento de peças e consumíveis necessários (exceto papel), incluindo serviços de operacionalização da solução". 
Observa-se que o contrato de outsourcing do HU compreende a cessão de uso de equipamentos de terceiros, em perfeitas condições de uso, além de estarem inclusos custos relacionados à manutenção e consumíveis necessários. Contudo, nesse contrato, não são incluídos os custos que envolvam o consumo de papel, insumo necessário à produção de impressos.

Nesse sentido, os custos com papel são caracterizados por serem variáveis. Entendem-se como variáveis aqueles custos que estão diretamente relacionados com o volume de produção; logo, quanto maior for o número de produção, maiores serão os custos variáveis totais (Wernke, 2001).

Ainda conforme definição de Wernke (2001), defende-se o custo tipo semivariável como sendo aquele que varia em função do volume de produção, mas não exatamente nas mesmas proporções.

Nesse processo de classificação de custos, inferem-se, a seguir, os gastos realizados nas impressoras para produção de impressos:

a) Custo Semivariável: Foram considerados os custos médios por impressão para cada página, considerando apenas os gastos com cartucho, sendo que, para as impressões coloridas, utilizou-se a média de $\mathrm{R} \$ 0,20$ por página e de $\mathrm{R} \$ 0,025$ por página preto e branco. Estas informações foram coletadas da Pesquisa de Campo a partir do contrato de outsourcing.

b) Custo Variável: Aqui estão classificadas as utilizações de Papel. Para definição do valor do gasto por pacote (resma), padronizou-se o mesmo valor considerado na análise de impressos realizados pela reprografia de $R \$ 14,47$ (quatorze reais e quarenta e sete centavos). A quantidade média de utilização de papel (folhas) no quadrimestre de setembro a dezembro de 2016 foi de 125.000 (cento e vinte e cinco mil) nas impressões colorida e/ou preto e branco.

$\mathrm{Na}$ apuração de custos, verificou-se a existência dos denominados custos fixos. Não obstante, esses custos fixos são entendidos como aqueles gastos que tendem a se 
manter constantes nas alterações de atividades operacionais, independentemente do valor de produção (Wernke, 2001).

Nesse sentido, como custos fixos foram identificadas as despesas com o aluguel de cada máquina e manutenção, já que são previstas contratualmente, pois a cessão de uso das máquinas não gerava quaisquer custos adicionais, conforme análise documental do contrato $\mathrm{n}^{0}$ 22/2015 da EBSERH/Sede.

Destaca-se que este estudo realiza uma projeção baseada em referência de curto prazo. Leone menciona que, para horizontes de curto alcance, as despesas e os custos são fixos, pois estão dentro de determinada faixa relevante de volume. Ao se utilizarem prazos longos, eles se comportariam do outro modo (Leone, 2010).

Durante a análise comparativa entre os custos de impressão e reprografia, observou-se que, a partir de janeiro de 2017 , os custos fixos demonstravam diminuição de valores, tendo em vista que houve o desligamento permanente de 3 impressoras do modelo Lermark 792 Xe 1 Lexmark 950.

Porém, o volume de impressão nas impressoras aumentou de 145.370 para 266.614, cujo maior pico foi atingido no mês de maio de 2017. Cabe ressaltar que os valores médios apurados, quando do funcionamento da máquina de reprografia, estava compreendido na média de 132.011.

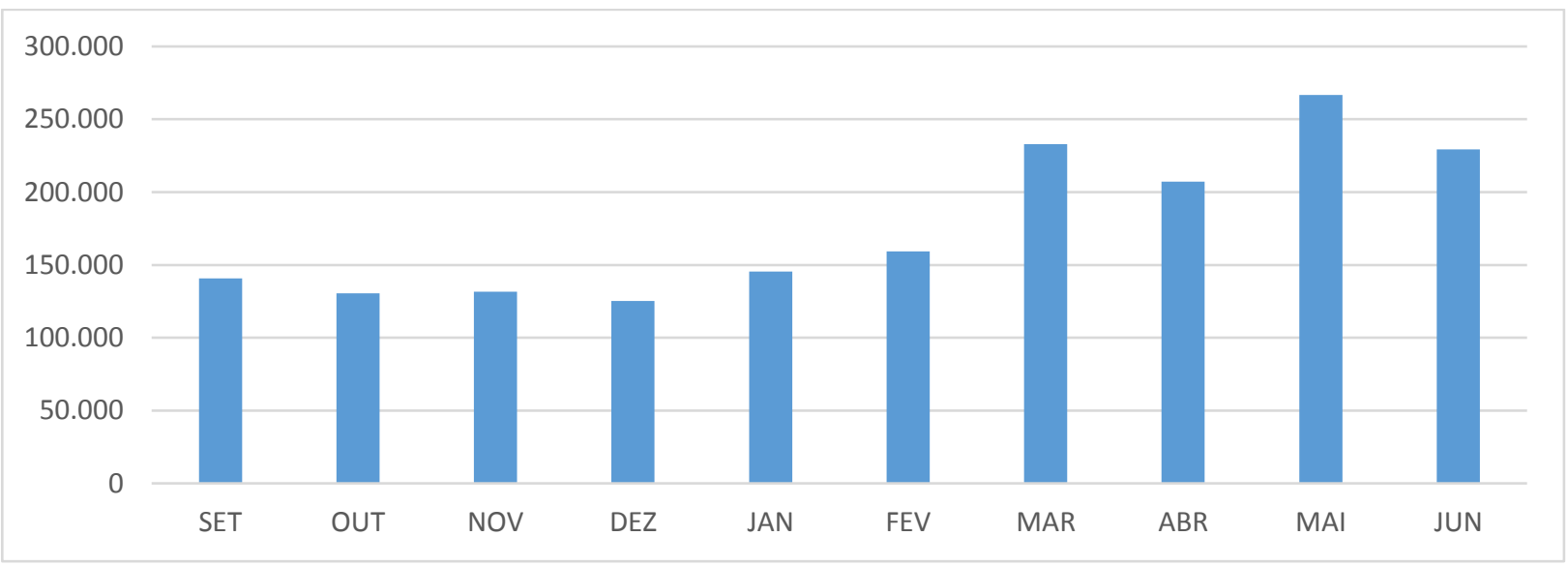

Figura 2. Quantidade de Páginas Impressas 2016/2017

Fonte: Elaborada pela autora. 
Logo, conforme Figura 2, nota-se crescente o deslocamento de impressões advindas das demandas de reprografia, sendo direcionadas às impressoras. Não foi possível mensurar a qualidade da utilização de impressoras nesse processo, porém constatou-se, na pesquisa de campo, que a utilização inadequada poderia ensejar manutenções mais frequentes, haja vista que a operação da máquina superava os limites técnicos de produção adequados.

Nesse sentido, avaliar a ociosidade dessas máquinas implicava geração de custos fixos, e a não utilização dessas impressoras resultava no desperdício de recursos financeiros.

Por conseguinte, analisou-se o custo de impressão por folha, considerando os custos fixos, semivariáveis e variáveis da produção das impressoras, resultando no Custo Médio de Impressão por Unidade (folha) de $\mathrm{R} \$ 0,396$. Desse modo, a decomposição da média de custos de impressão por unidade (folha) resulta dos seguintes custos: (a) Custo de impressão por Página Colorida: R\$ 0,713; (b) Custo de impressão por Página Preto e Branco: $\mathrm{R} \$ 0,079$.

Comparativamente, analisaram-se os Custos de Impressão por Unidade (folha) da Reprografia, resultando no valor de $R \$ 0,037$. Esta realiza apenas impressões em preto e branco. Observa-se que, na utilização de parâmetros proporcionais de custos entre Reprografia e Impressoras, obtêm-se uma diferença percentual de 53\% de 'vantajosidade' na utilização da Reprografia quando comparada aos gastos com impressões.

A memória de cálculo considerou os mesmos parâmetros produtivos para impressão e reprografia. As variáveis desenvolvidas foram: $C R(f)=$ Custo Unitário de Impressão por Página - Reprografia; $\mathrm{Cl}$ (f) = Custo Unitário de Impressão por Página Impressora. A notação percebida de 'vantajosidade' se traduz numa taxa percentual: $\mathrm{CR}(\mathrm{f})<\mathrm{Cl}(\mathrm{f})$.

$$
\text { Logo, } 0,037 / 0,079=0,43(100 \%) \cong 53 \% \text {. }
$$


Para análise de critério de rateio dos custos indiretos na produção de impressos, foram utilizadas, de forma indireta ao produto, ou seja, mediante estimativas, critérios de rateio e previsão do comportamento de custos.

Para Martins (2010, p. 79), nesta análise ocorre, em menor ou maior grau, certo subjetivismo, ou seja, a arbitrariedade sempre se mantém presente, porém a níveis aceitáveis. Além disso, o autor menciona que há recursos matemáticos e estatísticos que auxiliam esse problema, mas nem sempre é possível sua utilização.

O histórico de informações para o levantamento de informações sobre a composição e análises de custos entre impressão e reprografia são demonstrados nas Tabelas 2 e 3 a seguir.

Tabela 2

Apuração de Resultados de Custos em Reprografia

\begin{tabular}{lcc}
\hline Quantitativo de Equipamentos Analisados & $\mathbf{1}$ \\
Valor Total Gasto com Cartucho/Mês & $\mathrm{R} \$$ & 350,00 \\
Valor Total Gasto com Master/Mês & $\mathrm{R} \$$ & 201,84 \\
Valor Total Gasto com Papel/Mês & $\mathrm{R} \$$ & $2.170,50$ \\
Percentual de utilização adequada da máquina & \multicolumn{2}{c}{$87 \%$} \\
Custo de Manutenção/Mensal & $\mathrm{R} \$$ & 75,00 \\
\hline Custos Totais/Mensal & $\mathbf{R} \$$ & $\mathbf{2 . 7 9 7 , 3 4}$ \\
\hline
\end{tabular}

Nota. Fonte: Elaborada pela autora.

O Percentual de utilização adequada da máquina considera a relação entre o volume de produção e a capacidade de impressão. 
Contabilidade de Custos na Gestão Hospitalar: Um Estudo de Caso de Outsourcing no Contexto do Hospital Universitário de Juiz de Fora

Valéria Romão Pasqualini Nerio

Tabela 3

Apuração de Resultados de Custos em Impressoras

\begin{tabular}{|c|c|c|}
\hline \multirow[t]{2}{*}{ Quantitativo de Equipamentos Analisados } & \multicolumn{2}{|c|}{47} \\
\hline & Colorida & P\&B 1 \\
\hline Valor Total Gasto com Cartucho/Mês & $\mathrm{R} \$ 1.561,35$ & $\mathrm{R} \$ 3.038,37$ \\
\hline Quantitativo Médio de Impressões/Mês & 7.807 & 121.535 \\
\hline Valor Total Gasto com Aluguel/Mês & $\mathrm{R} \$ 3.780,00$ & $3.060,00$ \\
\hline Percentual de utilização adequada da máquina & Não informado & Não informado \\
\hline Custo de Manutenção/Mensal & \multicolumn{2}{|c|}{ Prerrogativa Contratual } \\
\hline Gasto com Papel/Mês (quant. Média) & $R \$ 225,93$ & $\mathrm{R} \$ 3.517,22$ \\
\hline Custos Totais/Mensal & $\mathrm{R} \$ \mathbf{5 . 5 6 7 , 2 8}$ & $\mathrm{R} \$ 9.615,584$ \\
\hline
\end{tabular}

Nota. Fonte: Elaborada pela autora.

1 P\&B é abreviação para impressões do tipo Preto e Branco.

Complementarmente, a Tabela 4 apresenta os custos para produção que atendam as demandas do Hospital, tendo por base informações obtidas em pesquisa documental.

Tabela 4

Comparativo de Custo/Mês do Quadrimestre entre setembro e dezembro de 2016

\begin{tabular}{lcc}
\hline Reprografia & $\mathbf{R} \mathbf{2 . 7 9 7 , 3 4}$ \\
Impressão P\&B & $\mathrm{R} \$$ & $9.615,58$ \\
Impressão Colorida & $\mathrm{R} \$$ & $5.567,28$ \\
\hline
\end{tabular}

Nota. Fonte: Elaborada pela autora.

Não obstante, faz-se necessária a demonstração gráfica apresentada pela Figura 3 sobre as comparações de custos (folha) entre os dispositivos de impressora e reprografia: 


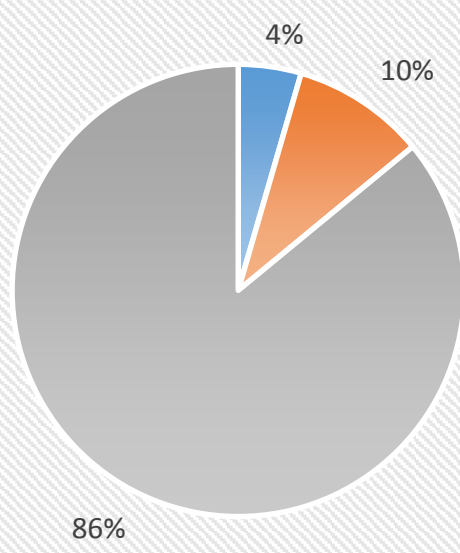

- Reprografia

- Impressão P\&B

- Impressão Colorida

Figura 3. Comparativo de Custos de Impressão (Folha)

Fonte: Elaborada pela autora.

Assim, compreende-se que tal comparativo demonstra que a maior parte da produção de impressos no âmbito do Hospital ocorre pelas impressões P\&B, ou seja, seu custo médio é de $\mathrm{R} \$ 0,079$ por página impressa (quando realizado por impressoras). Por outro lado, a menor participação em P\&B da reprografia significa um percentual de $4 \%$ dos custos de impressão por folha, ou seja, $\mathrm{R} \$ 0,037$ por página impressa.

\section{CONSIDERAÇÕES FINAIS}

A partir do método de procedimento de estudo de caso, nota-se que a reprografia possui menor participação nos processos de impressos do Hospital, mesmo possuindo os menores custos por unidade (folha): $\mathrm{R} \$ 0,037$.

O impresso mais oneroso é referente às impressões coloridas, apresentando custo de $R \$ 0,713$ por folha e, para impressos $P \& B$, com $R \$ 0,079 /$ follha. Ressalta-se ainda que o custo médio unitário (folha) entre impressoras é de $R \$ 0,396$. Dessa forma, este estudo atingiu seu objetivo inicial, descrevendo os custos de cada um dos equipamentos. 
Nesse sentido, constatou-se que o percentual de 'vantajosidade' da utilização de reprografia em relação à impressão P\&B é de 53\%, possibilitando, assim, maior economicidade, tendo em vista que as impressões $\mathrm{P} \& \mathrm{~B}$ realizadas por impressoras possuía custo de $\mathrm{R} \$ 0,079$.

Ressalta-se que, com base no estudo de custos, mensurou-se apuração de dispêndios mensais na comparação entre impressos de reprografia e impressora. Observou-se que a economicidade média é de $R \$ 3.150,00$ na utilização do ativo imobilizado, tendo em vista que os custos mensais de reprografia são de $R \$ 2.775,00$ e, de impressoras, de $R \$ 5.925,00$ (Quantidade: 75.000 páginas).

Acrescenta-se ainda o fato de que a inutilização da máquina de reprografia possibilitou o deslocamento de demanda de impressões para as impressoras e, por conseguinte, onerou o custo de maior vulto. Além disso, a sobrecarga da utilização dessas impressoras, cuja cessão contratual de uso dá-se por custos fixos de aluguel, gera ociosidade e potencializa desperdícios financeiros.

Portanto, constata-se que há viabilidade na utilização de máquinas de reprografia, tendo em vista o volume de produção de impressos em $\mathrm{P} \& \mathrm{~B}$, bem como os custos envolvidos entre os equipamentos considerados.

Espera-se que trabalhos desta natureza possam instigar instituições a se atentarem à análise de dados que, rotineiramente, são coletados dentro da própria instituição e que muito podem auxiliar na tomada de decisão. Sugerem-se, para pesquisas futuras, estudos comparados entre Hospitais da rede, cuja verificação de custeio resulte da apuração de sistema de custeios implantados nas organizações.

\section{REFERÊNCIAS}

Anjos, E. A., Moura, I. V., Brito, A. C., Aquino, B., Almeida, L. B., \& Pacheco. V. (2016). Outsourcing na indústria paranaense: um estudo empírico. Congresso Brasileiro de Custos, Porto de Galinhas, PE, Brasil, 23. 
Alves, A. S., \& Oliveira, A. S. D. O. (2012). Gestão estratégica de custos e tomada de decisão: um estudo de caso em uma instituição de educação básica no município de São Paulo. Bento Gonçalves, RS, Brasil, 19.

Colodetti, E. (2015). A Função Custo Como Instrumento de Tomada de Decisão. 4 Simpósio FUCAPE de Produção Científica. FUCAPE Business School, Vitória, ES, Brasil, 4.

Crepaldi et al. (2017). A Influência da Contabilidade de Custo na Tomada de Decisão. Recuperado de: <https://www.inesul.edu.br/revista/arquivos/arqidvol_31_1409171202.pdf>. Acesso em: 01 ago. 2019.

Dallora, M. E. L. do V., \& Forster, A. C. (2008). A importância da gestão de custos em hospitais de ensino: considerações teóricas. Medicina, 41( 2), 135-142.

Diehl, C. A., \& Souza, M. A. (2007). Um estudo sobre as publicações acerca do Custeio Baseado em Atividades (ABC) no Congresso Brasileiro de Custos: de 1997 a 2006. Anais do Congresso Brasileiro de Custos, João Pessoa, PB, Brasil, 14.

Diehl, C.. A., Souza, M. A., \& Domingos, I. E. C (2007). O uso da estatística descritiva na pesquisa em custos: Análise do XIV Congresso Brasileiro de Custos. ConTexto, Porto Alegre, RS, 7(12), 1-24.

Hospital Universitário de Juiz Fora. Carta de serviço ao cidadão de 2015. Recuperado de: <http://www.ebserh.gov.br/web/hu-ufjf/carta-de-servicos-ao-cidadao>. Acesso em: 10 jul. 2017.

Gil, A. C. Como elaborar projetos de pesquisa. (4a ed.). São Paulo: Atlas, 2002.

Hospitalares, E. B. S. Contrato no 22/2015: Impressão corporativa. Recuperado de: <http://sig.ebserh.gov.br/ >. Acesso em: 10 jul. 2017.

Lakatos, E. M., \& Marconi, M. A. (2003). Fundamentos de metodologia científica 1. (5a ed.). São Paulo: Atlas.

Leone, G. S. G. (2010). Curso de contabilidade de custos. (4a ed.). São Paulo: Atlas.

Martins, E. (2010). Contabilidade de custos. (10a ed.). São Paulo: Atlas.

Menezes, D. N. (2014). Análise dos Custos de Outsourcing de Serviços de Impressão. Anais do Simpósio Acadêmico de Engenharia de Produção. Universidade Federal de Viçosa. Viçosa/MG, Brasil, 09. 
Napoleão Filho, J., Alves, R. C., Pereira, L. F., Barreto, D., Nunes, P. M., \& Pacheco, A. S. V. (2013). Eficiência na Administração Pública: o modelo de outsourcing de impressão na Universidade Federal de Santa Catarina. Universidade Federal de Santa Catarina. Colóquio de Gestión Universitaria en Américas. Buenos Aires, Argentina, 13.

Padoveze, C. L. (2011). Controladoria estratégica e operacional. (2a ed.). rev. e atual. São Paulo: Cengage Learning.

Rodrigues, L. C. S., Silva, W. L., \& Carvalho, I. M. (2014, 1ํㅗㄹ semestre). Mudanças significativas ocorridas no ativo imobilizado devido à implantação das normas internacionais de Contabilidade - IFRS. Revista Inter Atividade, Andradina, SP, 2(1). <http://www.firb.br/editora/index.php/interatividade/article/view/115>.

Silva, A. O., Roratto, L., Servat, M. E., Dorneles, L., Polacinski, E. (2013). Gestão da Qualidade: Aplicação da Ferramenta 5W2H como Plano de Ação para Projeto de abertura de uma Empresa. Anais da $3^{\underline{a}}$ Semana Internacional das Engenharias da FAHOR. Faculdade Horizontina. Rio Grande do Sul, Brasil, 3.

Vieira et al. (2015). Gestão de Custos no Segmento Hospitalar: proposição de um modelo. Anais do Congresso Brasileiro de Custos. Foz do Iguaçu, PR, Brasil, 22.

Wernke, R. (2001). Gestão de Custos: uma abordagem prática. (1a ed.). São Paulo: Atlas.

Data de Submissão: 10/12/2018

Data de Aceite: 13/04/2020 